\title{
A Study on Comprehensive Experiment of Flight Technology Based on OBE
}

\author{
Shouxi Zhu \\ Flight college, Binzhou University, Binzhou 256603, China \\ Yujie Du* \\ Flight college, Binzhou University, Binzhou 256603, China \\ Wenlai Ma \\ Flight college, Binzhou University, Binzhou 256603, China
}

The research is financed by the ministry of education special task of humanities and social sciences research (Grant Nos. 17GDJC017) and teaching reform project of Binzhou University (Grant Nos. BYJYYB201618, BYJY2D201802).

\section{Abstract}

tFrom the perspective of practical ability of students' actual flight training and flight work, this paper studies on the comprehensive experimental system of flight technology. Then analyzes the problems and insufficiency existing in the original experiment construction, reforms the traditional experimental construction mode. Based on OBE, through build the relation matrix between knowledge, practice ability, experimental project and course, completed a strong comprehensive and perfect concrete design of comprehensive flight technology experiment. At last, problems in concrete implementation are discussed, and the advantages to promote students' ability of practice and the ability of using knowledge comprehensively have been proved by practice.

Keywords: OBE, Comprehensive experiment, Flight technology, Relation matrix

DOI: $10.7176 / \mathrm{JEP} / 10-36-02$

Publication date: December $31^{\text {st }} 2019$

\section{Introduction}

Engineering education is an important type of professional setting in China's higher education. The certification of engineering education is an internationally accepted quality assurance system for engineering education, and it is also an important basis for achieving international mutual recognition of engineering education and international recognition of engineer qualifications [1]. As China joined the Washington Agreement on June 19, 2013 as a preparatory member, more and more engineering majors in colleges and universities have begun to conduct engineering education professional certification in order to effectively improve the quality of talent training and to achieve the international substantial equivalent of professional quality [2].

The certification of engineering education major is a kind of qualified evaluation for higher engineering education majors. Its core concept is to focus on the students and pay attention to the continuous improvement of students' learning output and education quality, that is Outcome-based Education (OBE) [3]. As of the end of 2017, a total of 846 majors in 198 universities in China have passed the engineering education professional certification, marking that they have entered the "first square" of global engineering education.

The flight technology is a special engineeringmajor in China. This major cultivate application-oriented senior professionals who have advanced theoretical knowledge of civil aviation, have strong flight technology application and management capabilities, and can engage in the driving of domestic and international airlines in the field of civil aviation.

Although there is no international professional certification standard for flight technology currently, the concept of professional certification is universal. Guided by the OBE concept, it is of great significance to improve the quality of personnel training by conducting educational reforms in flight technology. The professional practice of flight technology major includes two parts: experimental training at the theoretical learning stage and flight training at the practice base. The purpose of theoretical learning and experimental training is to guide future actual flight, while traditional experimental settings are based on teachers and courses. It is not in line with the actual training of flight technology professionals, and it is impossible to achieve a seamless connection between the practical content of the two stages: the school and the training base. In order to solve this problem, under the guidance of the OBE concept, we reformed the flight technology specialty experiment, breaking the boundaries between theoretical courses, integrating the experimental items in the original course, and forming a comprehensive experiment in flight technology specialty.

\section{Experimental Setup and Problems of Flight Technology}

Comprehensive experiments are of great significance for improving the practical ability of flight students, which 
can help students to achieve a smooth transition from theoretical learning to flight training, and improving the effectiveness of flight training. According to the original experimental curriculum arrangement, although comprehensive experiments are set up in the experimental project, due to the limitation of experimental class hours and the problem of students' knowledge reserve, the experimental content is isolated and lacks connection, and the actual results are not good. The professional experimental projects and content often have the following common problems.

\subsection{Duplicate or Missing Experimental Content}

In the traditional experimental setting mode, the experimental content is often determined by the instructor based on the content of the curriculum. The main factors considered in the design of experimental projects and content include whether the requirements of the syllabus are met, whether the experimental facilities meet the needs, the difficulty of the experiment, the amount of experimental workload, etc. However, there is a lack of consideration of students' future job needs [4]. The independent experimental setting of the instructor will lead to duplication of experimental content or lack of necessary experimental content, which will greatly reduce the quality of talent training.

\subsection{The Experimental Content Is Not Connected}

In order to reduce the workload of experimental teaching, under the premise of meeting the minimum requirements for the type of experiment and content, teachers often tend to set up experimental projects with simple content and large groups. Obviously, the experimental items set by the instructors according to the curriculum content and their own needs will lead to a lack of necessary connections between the experimental content of different courses, and the experimental content cannot be effectively connected. Therefore, it is impossible to design scientific comprehensive experimental projects. This will cause comprehensive experiments to stay at a lower level and eventually become pseudo comprehensive experiments.

\subsection{The Experimental System Is Imperfect}

The non-independent setting of the experimental content directly led to the inability to form a systematic experimental system. Various experimental projects and theoretical knowledge are separated from each other. Substantive cooperation between lecturers cannot be conducted, and various experimental facilities cannot be effectively used [5]. On one hand, the experimental teaching workload of teachers is increased to a certain extent; on the other hand, the effect of experimental teaching cannot be guaranteed, and it cannot lay a good foundation for practical training for the practice base flight training.

\section{Construction of Comprehensive Experiments in Flight Technology}

The original experimental content of the flight technology major in our school was a non-independent course. The experimental content was only used as a supplement to theoretical knowledge. In order to solve the problems of scattered experimental hours, incomplete experimental system, and incomplete content, all experimental contents are integrated into specialized comprehensive experiment 1 and specialized comprehensive experiment 2, which are separately set up and are opened in the third and fourth semesters respectively, to a certain extent Problems such as the dispersion of experimental class hours are solved, as shown in Table 1.

Table 1. The Setting of Experimental Courses for Flight Technology

\begin{tabular}{ccc}
\hline Course name & Academic Hour & Semester \\
\hline Comprehensive Experiment 1 & 24 & 3 \\
Comprehensive Experiment 2 & 18 & 4 \\
\hline
\end{tabular}

According to the training objectives, students of this major will be engaged in pilot's work in the future, so the experimental content required by students in school must support the acquisition of flight technology. According to the process of acquiring knowledge, before entering the actual flight training phase, students first need to master the structure of the aircraft, be familiar with the use of various instruments, and conduct a preliminary flight experience. Therefore, the experimental content should be constructed through the following process.

\subsection{Breaking the Curriculum Boundaries and Establishing a Knowledge System}

Before constructing the experimental content, we must first sort out the knowledge points of all professional courses, break course boundaries, and analyze the inherent logical relationship between the knowledge points of each course. The theoretical knowledge of flight technology can be divided into two categories: theoretical knowledge of aircraft and theoretical knowledge of flight operations. In order to better design the experimental content, the knowledge system is combed according to the three main lines of aircraft structure, visual flight and instrument flight, as shown in Figure 1. 


1. Aircraft external structure (wings, landing gear, etc.) ? Aircraft
cockpit structure (instruments, buttons, joysticks, etc.)? Aircraft
internal structure (hydraulic system, engine, etc.)
2. Good weather? Visual flight rules? Visual flight? Basic pilot
instruments
3. Bad weather? Instrument flight rules? Instrument pilot? ILS
instrument system

Figure 1. Construction of Flight Technology Course System

\subsection{Determining The Practical Skills Required for The Theoretical Learning Phase}

The practical skills required in the theoretical study phase of the flight technology major must not only enhance and deepen the professional curriculum, but also lay a good foundation for flight training at the training base. According to the aviation theoretical knowledge system, the practical abilities required for flying students in the theoretical learning stage mainly include: aeronautical instrument reading, setting, fault diagnosis and troubleshooting capabilities; aeroengine and landing gear fault diagnosis and troubleshooting capabilities; identification and disposal of adverse weather capabilities; visual and instrument piloting capabilities; basic flight operations capabilities. As various problems may be encountered during actual flight, the flight operation basically covers all aviation theoretical knowledge and practical ability, and can be designed as a comprehensive experimental project.

\subsection{Construction of The Relationship Matrix between Knowledge and Practical ability}

We organically combine the aviation theoretical knowledge and practical ability required by flight students to build a matrix of relationships between practical ability, knowledge and curriculum. As shown in table 2 .

Table 2. Matrix of Practical Ability, Knowledge and Curriculum

\begin{tabular}{|c|c|c|}
\hline Practical Ability & Knowledge & Curriculum \\
\hline $\begin{array}{l}\text { Aviation instrument reading, } \\
\text { setting, fault diagnosis, } \\
\text { troubleshooting }\end{array}$ & $\begin{array}{c}\text { Principles of aviation } \\
\text { instrumentation; How to read } \\
\text { aviation instruments; Fault } \\
\text { diagnosis and elimination methods } \\
\text { for aviation instruments }\end{array}$ & $\begin{array}{c}\text { Civil aviation aircraft electrical, } \\
\text { instrument, and communication } \\
\text { systems; Navigation }\end{array}$ \\
\hline $\begin{array}{l}\text { Identification and disposal of } \\
\text { adverse weather }\end{array}$ & $\begin{array}{c}\text { Meteorological knowledge related } \\
\text { to flight safety; Use of } \\
\text { meteorological radar }\end{array}$ & Aeronautical meteorology \\
\hline Visual and instrument pilot skills & $\begin{array}{c}\text { Use of pilot instruments; } \\
\text { knowledge of landmark compass } \\
\text { navigation; sailing rules in the wind }\end{array}$ & $\begin{array}{l}\text { Navigation; Flight Principles; } \\
\text { Basics of Air Traffic Management }\end{array}$ \\
\hline $\begin{array}{l}\text { Engine and landing gear } \\
\text { troubleshooting }\end{array}$ & $\begin{array}{l}\text { Basic principles of aero engines; } \\
\text { basic principles of landing gear }\end{array}$ & $\begin{array}{c}\text { Aircraft system; Aviation power } \\
\text { unit }\end{array}$ \\
\hline Basic flight operating skills & $\begin{array}{l}\text { Includes all aviation-related } \\
\text { theoretical knowledge of flight }\end{array}$ & All professional courses \\
\hline \multicolumn{3}{|c|}{$\begin{array}{l}\text { In addition to the design of experimental projects to meet the training needs of the above practical ability, } \\
\text { we should also design other experimental projects according to the nature of the course to meet the needs of } \\
\text { deepening the level of theoretical knowledge [6]. According to the three types of demonstration, verification and } \\
\text { comprehensive, we design experimental projects separately. On the premise of meeting the requirements for the } \\
\text { training of flying students' practical ability and taking into account the needs of more difficult theoretical courses, } \\
\text { combined with the semester arrangements of related professional courses, finally formed The systematic flight } \\
\text { technology professional comprehensive experimental project (must do) is shown in Table } 3 \text {. It can be seen from } \\
\text { Table } 3 \text { that no matter what type of experiment, most of the experimental items contain knowledge points of } \\
\text { multiple courses, and they are all comprehensive experiments. Through professional comprehensive experiments, } \\
\text { it can help flight students form a systematic aviation theoretical knowledge system and acquire the basic } \\
\text { practical abilities required for flight training to reduce the flight elimination rate and improve the quality of flight } \\
\text { training, ensure the smooth development of flight work after graduation, and achieve expectations Training } \\
\text { objectives. }\end{array}$} \\
\hline
\end{tabular}


Table 3. Comprehensive Experimental Project of Flight Technology

\begin{tabular}{|c|c|c|c|}
\hline Experimental Project & Curriculum & $\begin{array}{l}\text { Experiment } \\
\text { type }\end{array}$ & $\begin{array}{l}\text { Academic } \\
\text { Hour }\end{array}$ \\
\hline Cockpit cognition & $\begin{array}{c}\text { Aircraft system; Civil aviation aircraft } \\
\text { electrical, instrument, and communication } \\
\text { systems; Navigation }\end{array}$ & \multirow{4}{*}{ Demonstration } & 3 \\
\hline $\begin{array}{l}\text { Aircraft structure } \\
\text { cognition }\end{array}$ & Aircraft system; Flight Principles & & 3 \\
\hline Weather chart recognition & $\begin{array}{l}\text { Civil aviation aircraft electrical, instrument, and } \\
\text { communication systems; Navigation; } \\
\text { Aeronautical meteorology }\end{array}$ & & 3 \\
\hline $\begin{array}{c}\text { Elementary flight simulation } \\
\text { experiment }\end{array}$ & All professional courses & & 6 \\
\hline Landing gear retractable & Aircraft system; Flight Principles & \multirow{3}{*}{ Verification } & 3 \\
\hline Engine disassembly & Aircraft system; Aviation power unit & & 3 \\
\hline Observation of clouds & Navigation; Aeronautical meteorology & & 3 \\
\hline $\begin{array}{l}\text { Comprehensive application } \\
\text { of civil aviation instrument }\end{array}$ & $\begin{array}{l}\text { Aircraft system; Civil aviation aircraft } \\
\text { electrical, instrument, and communication } \\
\text { systems; Navigation }\end{array}$ & \multirow{3}{*}{ Comprehensive } & 6 \\
\hline $\begin{array}{c}\text { Landmark and compass } \\
\text { navigation }\end{array}$ & Navigation; Basics of Air Traffic Management & & 3 \\
\hline $\begin{array}{l}\text { Advanced flight simulation } \\
\text { experiment }\end{array}$ & All professional courses & & 9 \\
\hline
\end{tabular}

\subsection{Construction Characteristics of Comprehensive Experiments}

(1) The experimental setup concept based on the work needs of students. The experimental setup is to meet the needs of talent training. Unscientific and irrational experimental setups are often reduced to human-based experiments and equipment-based experiments. The experimental project's support for practical ability training will be greatly weakened. Starting from the practical ability required by the students' work, based on the backward content of the experiment, clarify the knowledge points and related courses corresponding to the practical ability, and finally set up experimental projects, and propose an optimized design method for experimental settings to meet the requirements of talent training.

(2) The experimental design method with the task of forming a system knowledge system. The process of experimental construction fully follows the process of acquiring students' knowledge. Knowledge, abilities, courses, etc. are established through a relational matrix, so that all experimental projects and content, knowledge points, and practical abilities have a supporting relationship. Each experimental project has a clear role and value in talent training. The experimental setup is more scientific and more in line with the laws of education and teaching.

\section{Specific Implementation and Effects}

An experimental project in the comprehensive experiment of flight technology major can contain multiple knowledge points and cover multiple courses. It is a systematic, structured, and networked experimental system that is oriented to the needs of students' future work. In the implementation process, the experimental project must also fully consider the actual models used in flight training, such as Cessna-172, PA-44, Boeing 737, etc. Therefore, the experimental items in the comprehensive experimental system make full use of the experimental facilities of the Flight Academy's existing Cessna-172 simulator, PA-44 simulator, Boeing 737 aircraft, high simulation FTD and CBT experimental system.

According to the opened semester of the professional comprehensive experiments. And according to the principle of large groups of demonstration and verification experiments and small groups of comprehensive experiments, the experimental projects are reasonably allocated to CBT laboratories, high simulation FTD, Cessna-172, PA44 simulators and Boeing 737 aircraft. The arrangement of specific experimental projects at the same time follows the learning cognition rules of students from local to whole, from simple to complex, as shown in Table 4. 
Table 4. Professional Experimental Project Arrangement for Flight Technology

\begin{tabular}{ccc}
\hline Course name & Experimental Project & Semester \\
\hline $\begin{array}{c}\text { Comprehensive } \\
\text { Experiment 1 }\end{array}$ & $\begin{array}{c}\text { Cockpit cognition; Aircraft structure; cognition; Weather chart } \\
\text { recognition; Elementary flight simulation experiment; Landing gear } \\
\text { retractable; Engine disassembly; Observation of clouds }\end{array}$ & 3 \\
\hline $\begin{array}{c}\text { Comprehensive } \\
\text { Experiment 2 }\end{array}$ & $\begin{array}{c}\text { Comprehensive application of civil aviation instrument; Landmark and } \\
\text { compass navigation; Advanced flight simulation experiment }\end{array}$ & 4 \\
\hline
\end{tabular}

professional comprehensive experiment 1 in the 3rd semester mainly provides demonstration and verification experiments. After students have a deeper understanding of aircraft structure, cockpit and flightrelated meteorological problems, we will use a longer primary flight simulation experiments connect what you have learned in series. As the students' aviation theory major courses will be completed in the first three semesters, the professional comprehensive experiment 2 opened in the fourth semester mainly provides comprehensive experimental projects. Let students conduct flight simulation experiments on flight simulators which are completely consistent with flight training and work. By setting different equipment failures and flight scenarios, students can access the real flight training environment and experience the real experience before entering the training base. The working atmosphere of the flight realized the seamless connection of practical teaching in the two stages of the school and the training base.

The comprehensive experiment for flight technology specialty links the different aviation theory courses through scientific experimental content design, which improves the teaching effect of the theory courses, and to a certain extent, promotes the construction of the aviation students' theory knowledge system. The experimental process has effectively improved the comprehensive ability of students, and the bridge between the theoretical study of the school and the flight training at the training base has been established through comprehensive experiments. Through reasonable experiment settings, on the one hand, the utilization rate of various experimental equipment is effectively improved, and the workload of the instructor is reduced as much as possible, and the experimental effect is improved while the experimental class hours are unchanged. The practical flight training practice of flight students in our training base at the training base shows that the training of practical ability by flight students through professional comprehensive experiments can form a more systematic aviation theoretical system and practical ability. At the beginning of flight training, the tension is significantly reduced, the training start time is significantly reduced, the error rate is lower than the average level, and the flight elimination rate is reduced. At the same time, the passing rate of the theoretical examination for licenses organized by the Civil Aviation Administration has also been greatly improved.

\section{Conclusion}

Under the guidance of the OBE concept, this article re-understands the comprehensive experimental project from the perspective of the relationship between theoretical learning and student flight training and future work, and proposes a new comprehensive experimental setup concept. According to the students' actual flight training and practical skills required for flight work, by studying the internal connections between the courses, the boundaries between the courses were broken and the knowledge points were effectively integrated. Based on this, various experimental items of the course are transformed into professional comprehensive experiments, which enhances the systemicity and improves the utilization rate of experimental resources. By constructing a matrix of the relationship between experimental projects and students 'theoretical knowledge and practical abilities, using professional comprehensive experiments to link related courses has promoted students' comprehensive practical abilities, while improving the teaching effect of related theoretical courses, it is of great significance for the training of flight technology professionals.

\section{References}

Abdelmarouf H Mohieldein. (2017). Outcome-based approach to medical education towards academic programmes accreditation: A review article. Journal of the Pakistan Medical Association. 67(3):454-460.

Katherine Tan, Chong Mei Chan, Pathmawathy Subramaniam. (2018). The effectiveness of outcome based education on the competencies of nursing students: A systematic review. Nurse Education Today. 64:180.

Haidar M. Harmanani. (2017). An outcome-based assessment process for accrediting computing programmes[J]. European Journal of Engineering Education. 42(6):844-859.

Gouji Yamada, Toshiyuki Suzuki, Hiroki Takayanagi. (2009). Development of a Shock Tube for Improvement of Reentry Flight Technology[J]. Journal of the Japan Society for Aeronautical \& Spaceences. 57(670):426-436.

Fraher, Amy L. (2015). Technology-push, market-demand and the missing safety-pull: a case study of American Airlines Flight 587. New Technology Work \& Employment. 30(2):109-127.

Kai Virtanen, Tuomas Raivio, Raimo P. Hmlinen. (2004). Modeling Pilot's Sequential Maneuvering Decisions by a Multistage Influence Diagram[J]. Journal of Guidance Control \& Dynamics. 27(4):665--677. 